\title{
Histopathological and genetic changes proved the anti-cancer potential of free and nano-capsulated sinapic acid
}

\author{
Doaa A. Badr' ${ }^{1}$, Mohamed E. Amer², Wagih M. Abd-Elhay ${ }^{3}$, Mohamed S. M. Nasr ${ }^{3}$, Tamer M. M. Abuamara ${ }^{3}$, \\ Harbi Ali ${ }^{1}$, Aly F. Mohamed ${ }^{4 *}$, Maha A. Youssef ${ }^{5}$, Nasser S. Awwad ${ }^{6}$, Yi-Hsu Ju $^{7,8,9}$ and Ahmed E. Fazary ${ }^{1 *}$ (D)
}

\begin{abstract}
Cancer is known to be a fierce disease that causes a large percentage of the deaths worldwide. The common cancer treatments; chemotherapy, radiotherapy and surgery are known for their severe side effects; therefore scientists are working on finding solutions to reduce these drawbacks. One of these treatment systems is the sustained released drugs formulations, these systems depend on the encapsulation of the chemotherapy within an emulsifying agent, in order to obtain a slow drug release of low doses over long time intervals. In this study, the anti-cancer effects of free and encapsulated sinapic acid was tested against lung (A549), and colon ( $\mathrm{CaCO} 2)$ cancer cell lines, along with normal fibroblast cells (HFB4) as a negative control. MTT (3-(4,5-dimethylthiazol-2-yl)-2,5-diphenyltetrazolium bromide) assay was performed for $I C_{50}$ evaluation, also cell cycle assay was performed to detect cell cycle arrest status and related anti-apoptotic and pro-apoptotic; Blc-2, BAX, and P53 gene profile fold changes post cellular treatment. Data recorded revealed that encapsulated SA showed a lower toxicity than the free form to both cell lines and also to the normal cells. The cell cycle analysis showed a cell cycle arrest at the G2/M phase post cell treatment with the free and encapsulated sinapic acid accompanied with up regulation of Bax and P53 and a down regulation of Blc-2 genes in both cell lines. The data suggest a promising anti-cancer and anti-proliferative potential of free and encapsulated sinapic acid. Also they show that the anti-cancer effect of free and encapsulated sinapic acid is quite close.
\end{abstract}

Keywords: Sinapic acid, Nano-capsulated, Tween20, Lung cancer, Colon cancer

\section{Introduction}

The American cancer society estimated that $1,685,210$ new cancer cases and 595,690 cancer deaths were expected to occur in the United States in 2016 [1]. In Egypt a study was carried out on bases of national cancer registry program to determine the rate of cancer incidences taking place in Egypt and to see how the disease will develop by reaching 2050; the collected data from medical records of cancer centers, national tertiary care

\footnotetext{
*Correspondence: fahmy.aly@gmail.com; aefazary@gmail.com ${ }^{1}$ Applied Research Department, Research and Development Sector, Egyptian Organization for Biological Products and Vaccines (VACSERA Holding Company), 51 Wezaret El-Zeraa St., Agouza, Giza, Egypt

${ }^{4}$ The International Center for Advanced Researches (ICTAR- Egypt), Cairo, Egypt

Full list of author information is available at the end of the article
}

institutions, health insurance organizations, government-subsidized treatment program, and death records, showed that liver cancer $(23.8 \%)$ is very common and is considered a really serious problem in Egypt, followed by breast (15.4\%) and bladder cancers (6.9\%) per 100,000 individuals [2]. The most common treatment for cancer is chemotherapy combined with radiation or surgery. However, chemotherapy is known for its crucial side effects that have a psychological, physical and economic impact on the patient's life; as chemotherapy leads to hair loss, fatigue, vomiting, and in prolonged periods of treatments, it leads to heart, liver and kidney damages and malfunctions; all these physical collisions affect the patient's emotional and psychological state. In addition to these negative side effects, chemotherapy is given to patients in very large doses, on the one hand these large 
amounts of drug contribute to the occurrence of these negative effects, while on the other hand, it influences the patient's economic situation as chemotherapeutic drugs are very expensive [3]. Sinapic acid (SA, Scheme 1) is a member in the family of hydroxycinnamic acid derivatives; it has 3,5-dimethoxyl and 4-hydroxyl substitutions in the phenyl group of cinnamic acid. SA is widespread in the plant kingdom and commonly extracted from fruits, vegetables and grains such as rye and American cranberry. This acid has been known for its anti-oxidative, anxiolytic, anti-microbial effects, also it was investigated for its inflammatory effect; and it was proven that SA obtains its anti-inflammatory effect from the inhibition of NF-kB activation in macrophages which results in the prevention of iNOS, COX-2 and pro-inflammatory cytokines, in addition, it has shown an anti-edema effect [4]. Moreover, SA shows an anti-cancer potential; since 4-vinylsyringol, which is a de-carboxylation product of SA, has the ability to suppress carcinogenesis and induce inflammatory cytokines [5]. These side effects of chemotherapy resulting from the drug effects itself in addition to the drug administration in large dosage led scientists to think of solutions in order to reduce these adverse effects. One of these solutions is the encapsulation of the chemotherapeutic drug in non-ionic surfactant capsules such as polysorbate 20 , in order to develop an extended and gradual release drug delivery system, therefore the drug would last for a prolonged period in the biological system after drug administration, so the body will be able to utilize the up taken drug and the patient will not be obliged to take the same large amounts of the drug which hopefully will reduce the adverse effects of chemotherapy. Polysorbates mainly consist of fatty acid esters of polyethoxy sorbitan and are commercialized under many names such as Tween and Monitan. They are used as emulsifiers, defoamers, dispersants, and stabilizers in food, cosmetics, and biodegradation media. Tween 20 is formed by the ethoxylation of sorbitan before the addition of lauric acid, it is usually used as an emulsifier in pharmaceutical applications [6]. This research study aims to investigate the anti-proliferative and anti-cancer

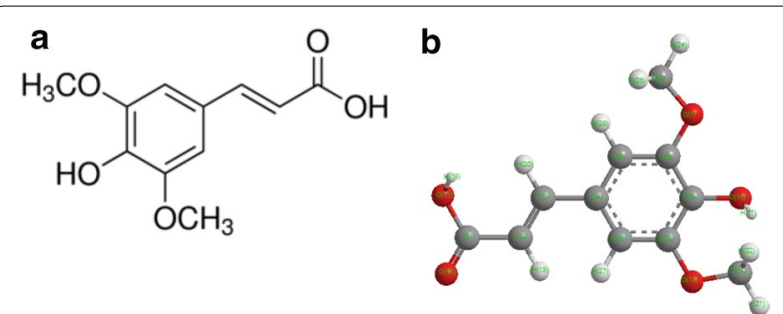

Scheme 1 Molecular structure of $\mathbf{a}$ sinapic acid and $\mathbf{b}$ its computer generated model potentials of free and nano-capsulated SA against colon and lung cancer cells and to observe their effect on cell cycle and the related apoptotic gene profiles.

\section{Materials and methods}

\section{Cell lines, chemicals, and materials}

Human colorectal carcinoma $\mathrm{CaCo} 2$ was obtained from the American Type Culture Collection (ATCC HTB$37^{\mathrm{TM}}$, ATCC, Manassas, VA) and Human lung carcinoma A549 cell line was obtained from the Leibniz Institute DSMZ-German Collection of Microorganisms and Cell Cultures (Braunschweig, Germany). Human normal fibroblast cells (HFB4) were purchased from the American Type Culture Collection (Rockville, Maryland, USA). All the chemicals, materials, and organic solvents used in this work were of analytical reagent grade and were used without further purifications Free and Tween 20 encapsulated SA, were kindly supplied from cell culture department (VACSERA-Egypt). SA was kindly supplied by (Sigma-Aldrich, USA). It was diluted in Dimethyl sulfoxide (DMSO) (Sigma-Aldrich, UK). SA was diluted in serum and phenol red-free medium to obtain $1 \mathrm{mM}$ final concentration. Nano capsulation of SA was performed in the nanotech center 6th October city-Giza-Egypt according to the manufacturer protocol.

\section{MTT assay}

Human colorectal (CaCo2) and lung (A549) cancer cells and normal human fibroblast (HFB4) cells were propagated in $75 \mathrm{~cm}^{2}$ cell culture flasks using RPMI-1640 medium and DMEM MEDIA purchased from Gibco, Life Technologies (Paisley, United Kingdom), respectively supplemented with $10 \%(\mathrm{v} / \mathrm{v})$ fetal bovine serum $\left(\mathrm{GIBCO}^{\mathrm{TM}}\right.$, New York, USA) and incubated in $5 \%(\mathrm{v} / \mathrm{v})$ $\mathrm{CO}_{2}$ incubator at $37^{\circ} \mathrm{C}$. Confluent cells were detached using $0.25 \%(\mathrm{w} / \mathrm{v})$ trypsin solution and $0.05 \%(\mathrm{v} / \mathrm{v})$ EDTA $\left(\right.$ GIBCO $^{\mathrm{TM}}$, New York, USA) for $5 \mathrm{~min}$. Detached cells were cold centrifuged using Jouan ki22 Refrigerated Centrifuge (LABEQUIP LTD, France). Cell pellets were re-suspended in growth medium. Cells were plated at a concentration of $2 \times 10^{5}$ cells $/ \mathrm{ml}$ in 96 -well cell culture plates (TPP, Switzerland), the plates were incubated at $37{ }^{\circ} \mathrm{C}$ for 24 in an incubator (Mini Artic, Jouan, France) to achieve confluence. The medium was decanted and fresh medium containing various concentrations of free and encapsulated SA was added for cytotoxicity assessment using colorimetric MTT assay. Dead cells were washed out using phosphate-buffered-saline (PBS) and $50 \mu \mathrm{l}$ of MTT obtained from SERVA, Germany. Stock solution $(0.5 \mathrm{mg} / \mathrm{ml})$ was added to each well. After $4 \mathrm{~h}$ incubation, the supernatants were discarded and the Formosan crystals were solubilized using $50 \mu \mathrm{l}$ per well of dimethyl sulfoxide (DMSO). Plates were incubated in the dark 
for $30 \mathrm{~min}$ at $37^{\circ} \mathrm{C}$ and absorbance was determined at a wavelength of $570 \mathrm{~nm}$ using a micro plate reader Elx-800 (Biotek, USA). Cell viability percentage was calculated using the following formula: Cell viability (\%)=OD of treated wells $\times 100 / \mathrm{OD}$ of control wells. The cell viability $\%$ was plotted against the tested acid concentrations. The $\mathrm{IC}_{50}$ values of test free and encapsulated SA were determined using the Masterplex-2010 software program. The effect of SA as an anticancer agent was examined by evaluating the cytotoxic potential of the free and encapsulated acid in $\mathrm{CaCo} 2$ and $\mathrm{A} 549$ cells pretreated for 1 day with serially diluted SA both free and nano-capsulated. Morphological alterations of cells were analyzed using an inverted microscope (Nikon, Japan).

\section{Cell cycle analysis}

$\mathrm{CaCo} 2$ and A549 cells pre-cultured in $25 \mathrm{~cm}^{2}$ surface area cell culture flasks (TPP, Switzerland) were treated with the $\mathrm{IC}_{50}$ values of free and nano-capsulated SA, for $24 \mathrm{~h}$. For cell cycle analysis, the detached and residual live cells were harvested and fixed gently with $70 \%(\mathrm{v} / \mathrm{v})$ methanol (Sigma-Aldrich, UK). and kept at $4{ }^{\circ} \mathrm{C}$. Cells were re-suspended in PBS containing $40 \mu \mathrm{g} / \mathrm{ml}$ PI and $0.1 \mathrm{mg} / \mathrm{ml}$ RNase and $0.1 \%(\mathrm{v} / \mathrm{v})$ Triton X-100 purchased from Sigma-Aldrich, UK, in a dark room. After $30 \mathrm{~min}$ at $37^{\circ} \mathrm{C}$, the cells were analyzed using a flow-cytometer (Becton-Dickinson, San Jose, CA, USA) equipped with an argon ion laser at a wavelength of $488 \mathrm{~nm}$. The cell cycle and sub-G1 group were determined and analyzed, as described previously.

\section{mRNA expression of cell apoptosis-related genes}

Total RNA was extracted from control and $\mathrm{CaCo} 2$ and A549 FSA/Nanocapsulated SA treated cells using a Gene JET RNA Purification kit (Fermantus, UK) according to the manufacturer's protocol. The concentration and integrity of RNA were assessed spectrophotometrically at $260 / 280 \mathrm{~nm}$ ratio and by gel electrophoresis, respectively. First-strand cDNA was synthesized with $1 \mu \mathrm{g}$ of total RNA using a Quantitate Reverse Transcription Kit (Qiagen, Germany) in accordance with the manufacturer's instructions. These samples were subsequently frozen at $-80{ }^{\circ} \mathrm{C}$ until use for determination of the expression levels of P53, Bax and Bcl-2 genes using real-time PCR. Quantitative real-time PCR was performed on a RotorGene Q cycler (Qiagen, Germany) using a QuantiTect SYBR Green PCR kits (Qiagen, Germany) and forward and reverse primers for each gene. The nucleic acid sequences of the primers were as follows: P53 (F $5^{\prime}$-CCC CTCCTGGCCCCTGTCATCTTC -3', R 5'-GCAGCG CCTCACAACCTCCGTCAT-3' ${ }^{\prime}$ ), Bax (F 5'-GTTTCA TCC AGG ATC GAG CAG-3', R 5'-CATCTT CTT CCA GAT GGT GA-3') and anti-apoptotic gene Bcl-2
(F 5'-CCTGTG GAT GAC TGA GTA CC-3', R 5'-GAG ACA GCC AGG AGA AAT CA-3') compared to the house keeping gene $\beta$-actin as a control (F $5^{\prime}$-GTGACA TCCACACCCAGAGG-3', R 5'-ACAGGATGTCAA AACTGCCC-3'). Real-time PCR mixture consisted of $12.5 \mu \mathrm{l} 2 \mathrm{x}$ SYBR Green PCR Master Mix, $1 \mu \mathrm{l}$ of each primer $(10 \mu \mathrm{mol} / \mu \mathrm{l}), 2 \mu \mathrm{l} \mathrm{cDNA}$ and $8.5 \mu \mathrm{l}$ Rnase-free water in a total volume of $25 \mu \mathrm{l}$. Amplification conditions and cycle counts were: $95{ }^{\circ} \mathrm{C}$ for $15 \mathrm{~min}$ for the initial activation, followed by 40 cycles of denaturation at $94{ }^{\circ} \mathrm{C}$ for $15 \mathrm{~s}$, annealing at $60{ }^{\circ} \mathrm{C}$ for $30 \mathrm{~s}$ and extension at $72{ }^{\circ} \mathrm{C}$ for $30 \mathrm{~s}$. Melting curves were performed after real-time PCR to demonstrate the specific amplification of single products of interest. A standard curve assay was performed to determine the amplification efficiency of the primers used. Expression of target genes (P53, Bax and Bcl-2) were accomplished using the comparative $2^{-\Delta \Delta} \mathrm{Ct}$ method with the $\beta$-actin gene as a house keeping gene to normalize the level of target gene expression. ${ }^{\Delta \Delta} \mathrm{Ct}$ is the difference between the mean ${ }^{\Delta} \mathrm{Ct}$ (treatment group) and mean ${ }^{\Delta} \mathrm{Ct}$ (control group), where ${ }^{\Delta} \mathrm{Ct}$ is the difference between the mean $\mathrm{Ct}$ gene of interest and the mean $\mathrm{Ct}$ internal control gene in each sample. Logarithmic transformation was performed on fold change values before being statistically analyzed, using the fold change values of three replicates for each gene.

\section{Statistical analysis}

All experiments were carried out in three independent tests. Data were expressed as mean standard deviation (SD) and analyzed using one-way analysis of variance (ANOVA). Significance difference between treated and untreated cells was determined using one way ANOVA. The results were considered statistically significant at probability $(\mathrm{P}<0.05)$.

\section{Results}

The recorded data revealed that the bioactivity of free and encapsulated SA are quite close, so it will be advantageous to use the encapsulated SA for cancer treatment in order to reduce any possible side effects and to minimize the drug up-take (Fig. 1). In this study, the recorded data showed that free and encapsulated SA were biocompatible to the three tested cell lines. Also data revealed that the cytotoxic effect and related $\mathrm{IC}_{50}$ values of both free and encapsulated SA were concentration and cell type dependent (Figs. 1 and 2). The gene profile was relevant to the effect of drug in its free or nano-capsulated form as Bax gene showed significant 5.2/4.7-fold increase for A549 and 2.9/3.9-fold increase for $\mathrm{CaCo} 2$. Also, P53 gene profile showed an elevated expression translated as 11.19/6.6-fold increase for A549 and 5.58/2.42-fold increase for $\mathrm{CaCo}$. While $\mathrm{Bcl}-2$ as anti-apoptotic gene 


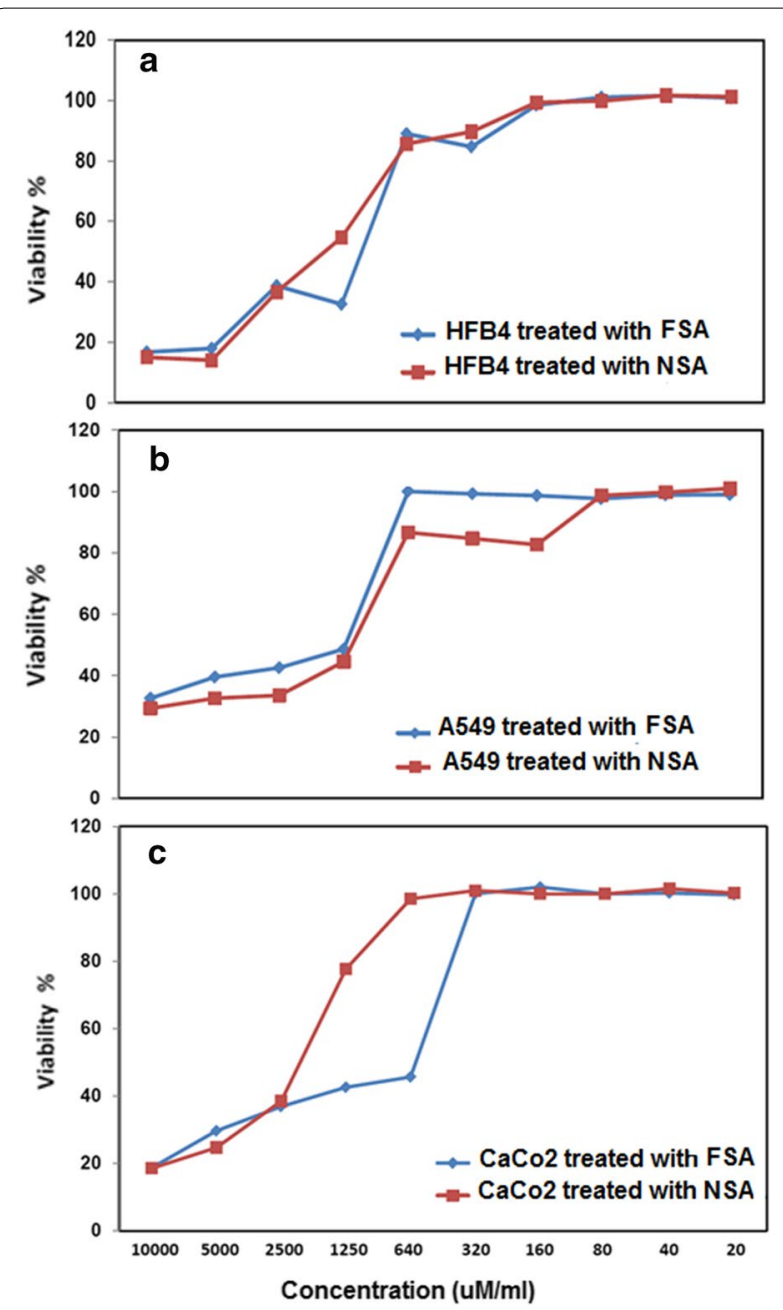

Fig. 1 Evaluation of viability \% of a HFB4 normal cell Line, and $\mathbf{b}$ A549 lung and $\mathbf{c} \mathrm{CaCo} 2$ colon cancer cell lines treated with free sinapic acid (FSA) and nano-capsulated sinapic acid (NSA)

showed 0.47/0.3-fold decrease for A549, 0.84/0.22-fold decrease for $\mathrm{CaCo} 2$ (Fig. 3). In the meantime, cell cycle analysis showed a cell cycle arrest at the G2/M phase post cellular treatment with free and encapsulated SA. A549 and $\mathrm{CaCo} 2$ showed a significant cellular arrest in the G2/M phase $(\mathrm{P}<0.05)$ while an insignificant $\%$ of arrested cells was detected in case of A549 cell line treated with free SA $(P>0.05)$. Also, this cell arresting was accompanied with cell apoptosis in a significant ratio compared with that induced in cell control $(\mathrm{P}<0.05)$. Data recorded revealed that nano-capsulated SA showed a substantial apoptotic \% than the non-capsulated form (Figs. 4, 5, 6, 7).

Apoptosis of FSA/NSA treated cells was traced via monitoring of apoptotic genes profile as it was noticed that proapoptotic genes (P53-Bax) were significantly up-regulated in case of cell treatment with both free and nano-capsulated SA compared with control and their expression was cell type dependent as it was elevated in case of $\mathrm{A} 549$ than in $\mathrm{CaCo} 2$ in an insignificant way $(\mathrm{P}<0.05)$. In the meantime, caspase gene was significantly up regulated post different treatment compared with its values in untreated cell control. Concurrently Casp-3 was significantly $(\mathrm{P}>0.05)$ elevated than its values in $\mathrm{CaCo} 2$ cells treated with FSA/NSA but not in case of NSA/A549. Also, anti-apoptotic gene eMMP1 was significantly $(\mathrm{P}<0.05)$ elevated in case of cell treatment with FSA/A549, NSA/A549, FSA/CaCo2 than NSA/CaCo2. Finally, $\mathrm{Bcl}-2$ gene was significantly up regulated in case if $\mathrm{CaCo} 2$ cells treated with FSA than in case of NSA. The opposite was detected in case of A549 cells treated with both free and nano-capsulated SA. Apoptotic profile of both lung and colon cancer cell lines were traced. Data recorded revealed that pro-apoptotic genes P53 and Bax were significantly up regulated $(\mathrm{P}<0.05)$ compared with its value in control untreated cells. Up regulation of P53 was significantly up regulated in FSA treated A549 cell than the rest of test groups $(\mathrm{P}<0.05)$. caspase- 3 gene in both FSA and NSA treated cells was insignificantly elevated between the treated free and nanocapsulated A549 and $\mathrm{CaCo} 2$ cells than in case of cell control and between the test groups for each cell line $(\mathrm{P}>0.05)$. Also, $\mathrm{Bcl}-2$ showed an insignificant $(P>0.05)$ down regulation than in case of NSA/CaCo2 treated cells, while MMP1 was

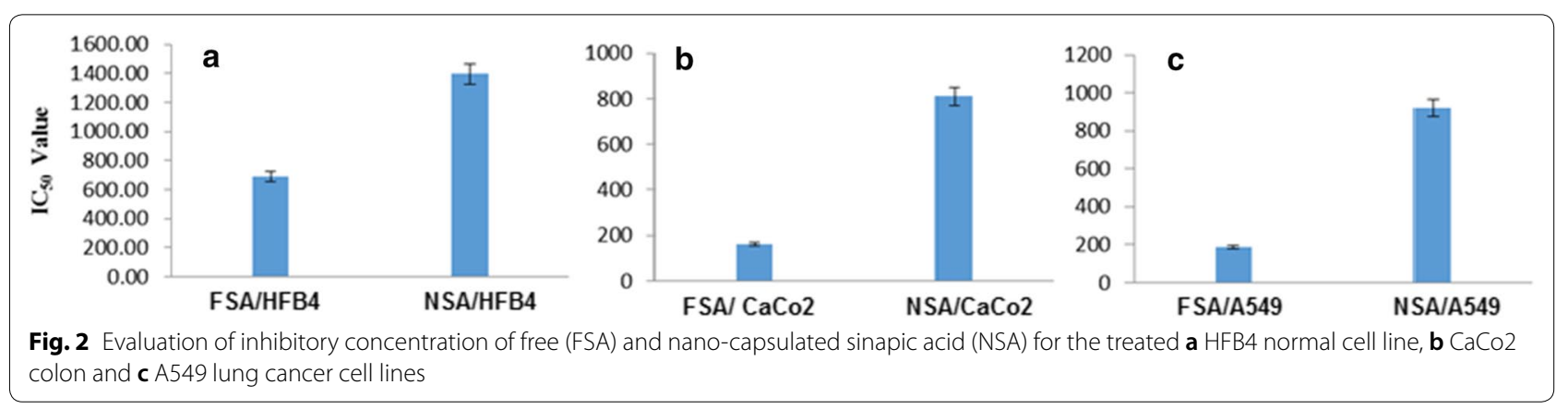




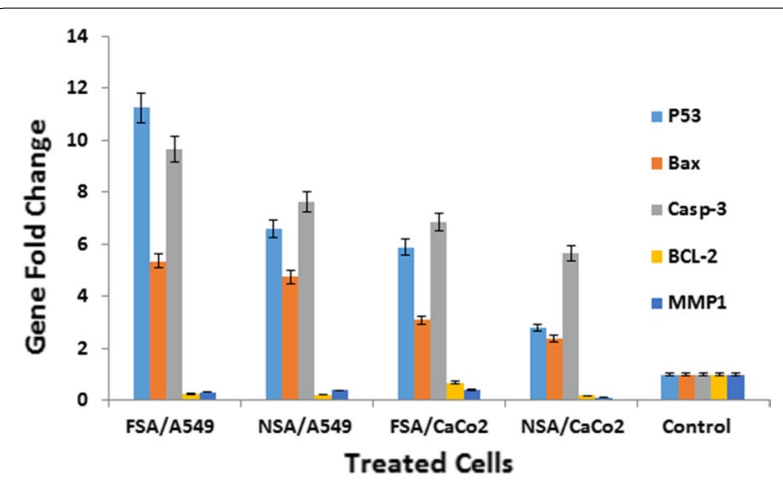

Fig. 3 Gene folds change for the treated cells: HFB4 normal control cell line, A549 lung and CaCo2 colon cancer cell lines treated with free sinapic acid (FSA) and nano-capsulated sinapic acid (NSA)

significantly $(\mathrm{P}<0.05)$ down regulated in case of NSA/ $\mathrm{CaCo} 2$ treated cells than the rest of test groups (Fig. 3). Evaluation of ROS as antioxidant was determined using ELISA; Recorded data revealed that ROS was elevated under the effect of nano-capsulated SA than in case of free one and its level was cell type dependent. The level was not significantly elevated in both formulae of SA in both cell lines (Fig. 7).

\section{Discussions}

Cancer initiation and progression is linked to the immune system as well as to genes that are responsible for controlling the cell cycle. The relation between cancer development and immune cells have taken interest by researches which studied the SA's anti-proliferative potential over the past years; specially its effect on the role of macrophages in cancer development; since they have been reported to acquire an important role in cancer initiation and progression. During tumor initiation, they create an inflammatory environment that is mutagenic and promotes tumor growth. Macrophages stimulate angiogenesis which favors the development of cancer; as the angiogenesis enhances tumor cell migration, invasion, and metastasis and suppresses anti-tumor immunity. Also they promote cancer cells extravasations,

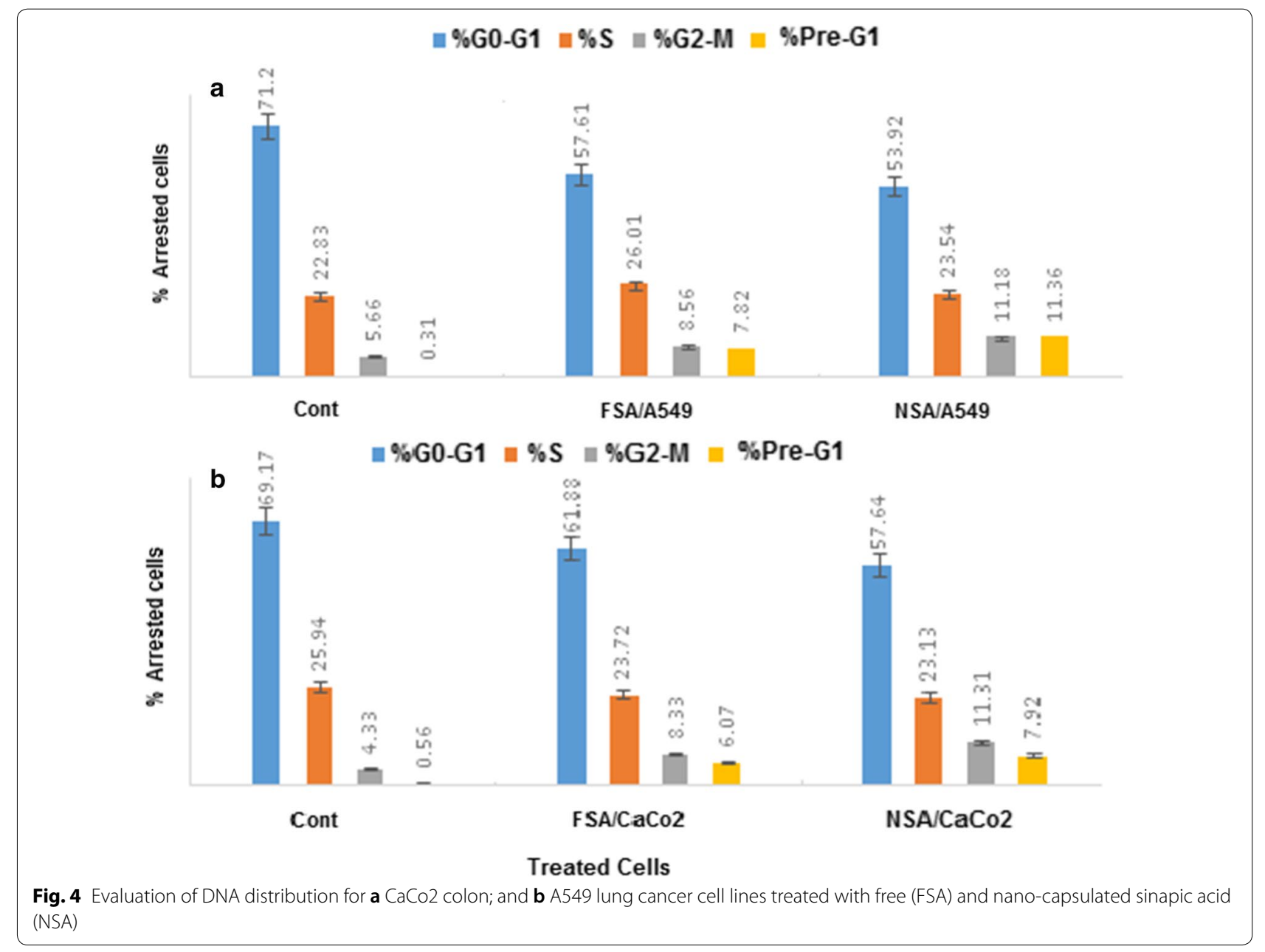




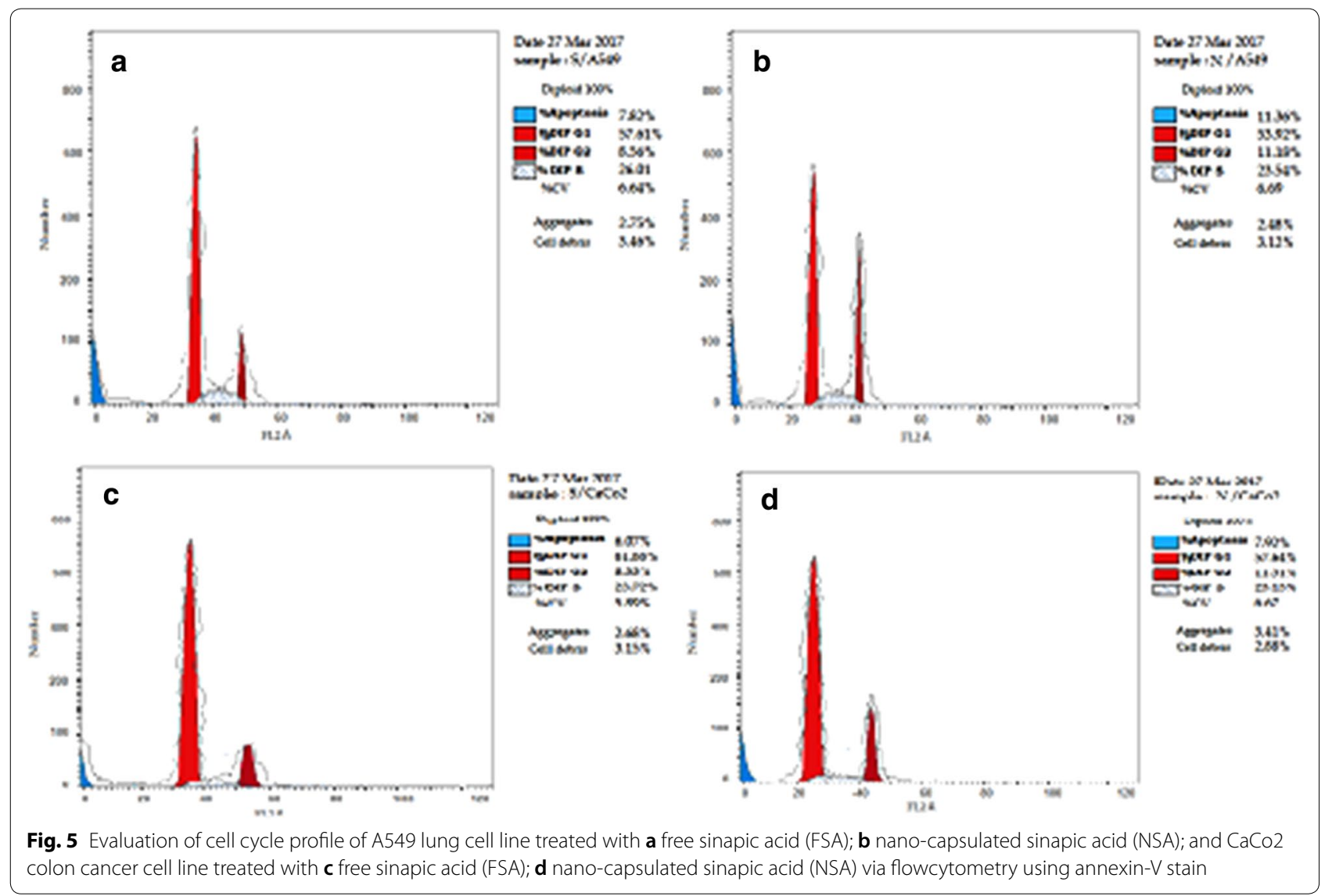

survival and subsequent growth [7]. The nuclear factorkappa B (NF-kB) in macrophages plays the main role in immune responses and inflammatory status regulations, yet the improper regulation of NF- $\mathrm{kB}$ has been linked to cancer occurrence [8]. The studies done by Yun and others in 2008 showed that SA suppresses the expression of pro-inflammatory mediators such as inducible nitric oxide syntheses, cyclooxygenase-2, tumor necrosis factor- $\alpha$, and interleukin- $1 \beta$ through the inactivation of NF-kB. These anti-inflammatory effects of SA were linked to its anti-cancer effect. Upon the investigation of the anti-cancer effect of SA, the results showed that it exerts an inhibitory effect against cancerous colon cells, however it had a low impact on breast cancer cells. This study was in agreement with our results despite the use of different cell lines and gene profile [9]. Regarding the anti-proliferative potential and related $\mathrm{IC}_{50}$ value of $\mathrm{SA}$ to cancer cell lines [10], as they reported that the antiproliferative effect of SA along with other phenolic acids were tested on T47D breast cancer cell line using apoptosis and RT-PCR assays, and the results indicated that SA decreased the proliferation rate by $20 \%$ with an $\mathrm{IC}_{50}$ of $7 \times 10^{-11} \mathrm{M}$. However, in the published research [11], results of testing SA on MK-1, HeLa and B16F10 showed that the acid was inactive against the three cancer cell lines $\left(\mathrm{GI}_{50}>100 \mu \mathrm{g} / \mathrm{ml}\right)$ and it was suggested that the presence of 3, 4-dihydroxyphenyl group is essential for SA to acquire an anti-proliferative effect. In a study done previously [12] they tested the apoptotic effect of SA on human laryngeal carcinoma cell line (HEp-2). The cytotoxicity of SA was determined by MTT assay, morphological changes, and levels of reactive oxygen species, mitochondrial membrane potential and cell cycle analysis by flow cytometry. They determined the effective dose of SA to be $125.23 \mu \mathrm{M} / \mathrm{ml}$ for $24 \mathrm{~h}$ and $117.81 \mu \mathrm{M} / \mathrm{ml}$ for $48 \mathrm{~h}$ and the MTT results showed that the cytotoxicity of SA is dose and time dependent. Also their results showed an increased level in ROS in HEp-2 cells treated with $\mathrm{IC}_{50}$ concentration, Also, the $\mathrm{IC}_{50}$ of free SA and nano-SA was cell type dependent and the nano-from showed insignificant variation on both $\mathrm{A} 549$ and $\mathrm{CaCo} 2$ cells and the free form was more effective than the capsulated form. On contrary it was reported that normal skin cell (HFB4) can withstand more than cancer cells. And it is known that elevated levels of ROS cause oxidative stress leading to cellular damage and the activations of the mitochondria dependent pathway of apoptosis; and this is the mechanism on which many cancer drugs are based. In addition, 

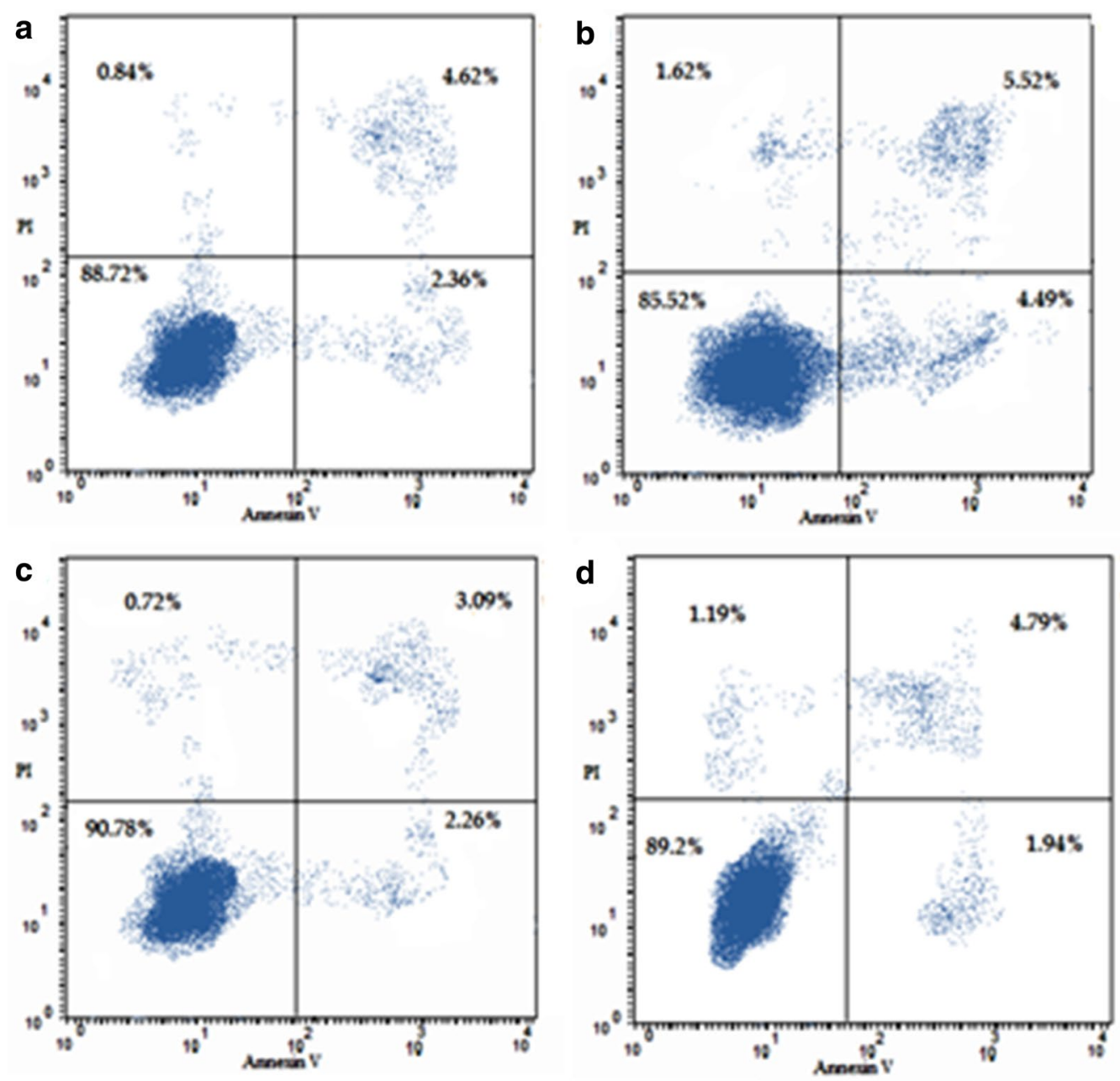

Fig. 6 Evaluation of apoptotic profile of both: A549 Lung Cell Line treated with a free sinapic acid (FSA); $\mathbf{b}$ nano-capsulated sinapic acid (NSA); and $\mathrm{CaCo} 2$ colon cancer cell line treated with $\mathbf{c}$ free sinapic acid (FSA); $\mathbf{d}$ nano-capsulated sinapic acid (NSA) via flowcytometry using PI stain

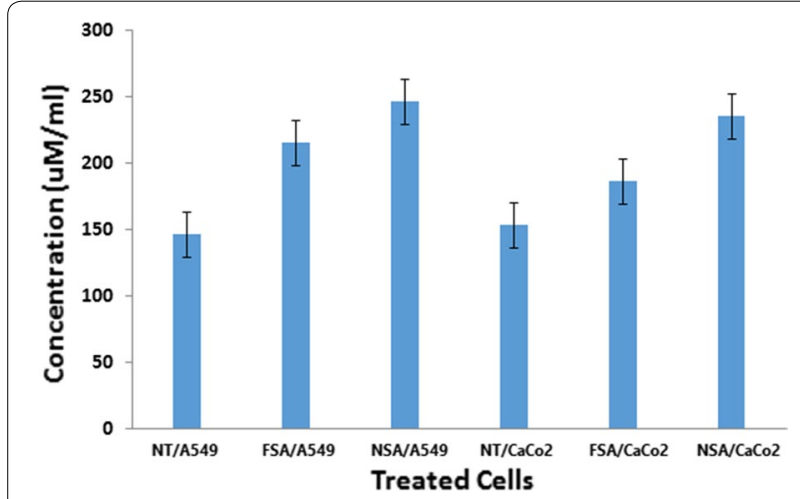

Fig. 7 Anti reactive oxygen species (ROS) of non-treated (NT) A549 lung and $\mathrm{CaCo} 2$ colon cancer cell lines and the treated cells with free sinapic acid (FSA) nano-capsulated sinapic acid (NSA) morphological changes that are apoptosis like were observed in the treated cells, such as membrane blebbing, cell shrinkage, chromatin condensation, nuclear fragmentation, apoptotic bodies and loss of adhesion. The results of the flow cytometry showed an early cell cycle arrest at G0/G1 phase in the treated cells as most anti-cancer drugs induce a cell cycle arrest at G0/G1 or $\mathrm{G} 2 / \mathrm{M}$ phases. The recent findings [12] were in agreement to our results which suggest that the effect of both free and capsulated SA is concentration, cell type and time dependent; and that both free and encapsulated SA have almost the same effects in vitro. Also they showed an elevation in the expression of the pro-apoptotic genes Bax and P53 in both tested cell line CaCo2 and A549, while a down regulation in the anti-apoptotic gene $\mathrm{Bcl}-2$ 


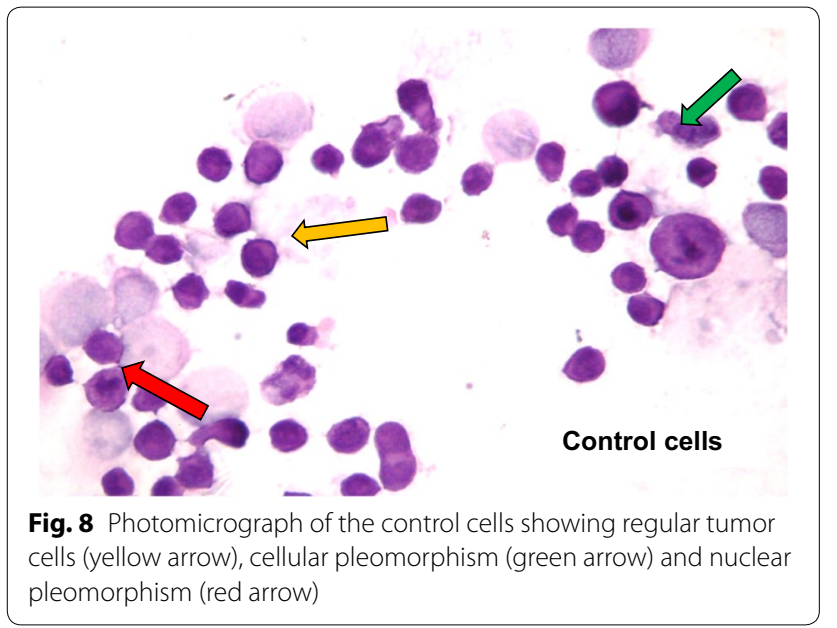

was noticed, as well as a noteworthy cell cycle arrest at G2/M was observed post treatment with free and capsulated SA in both cell lines. In another study [13], they discussed the HDAC (Histone deacetylase) inhibitory and anti-proliferative effect of sinapic acid, was found that the HDAC inhibition was feebly accomplished by SA due to its hydrophobicity, however it was shown that SA acquired an efficient anti-proliferative effect against HeLa and HT29 cell lines, although it was not sufficient as a single drug therapy, they suggested that this insufficient anti-proliferative effect may be caused by the anti-oxidants present in plant extracts and that the incorporation of SA with other anti-cancer drugs needs to be investigated. The outcomes of our study along with the conclusions and results of previous researches that were

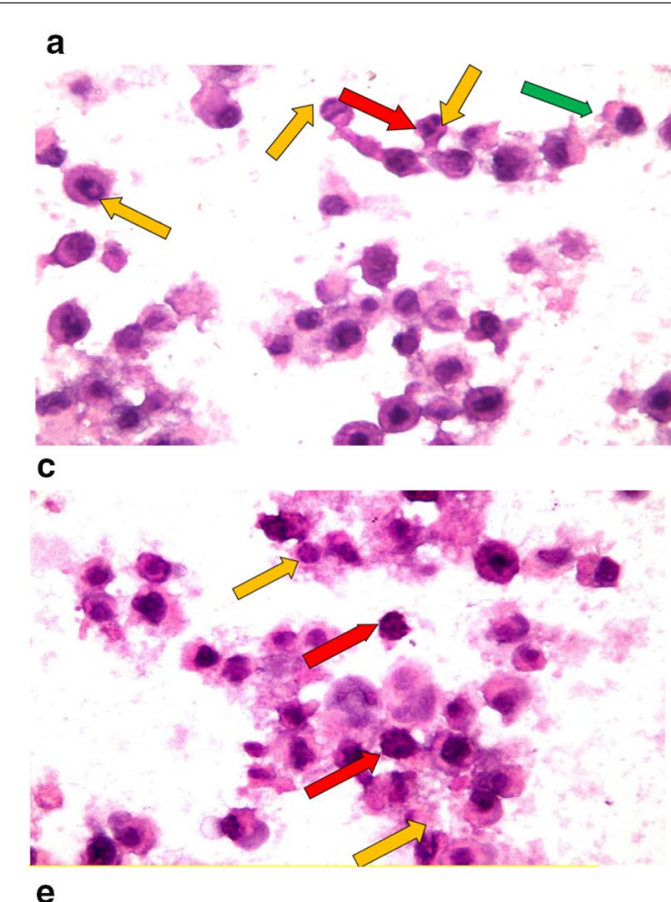

\section{b}

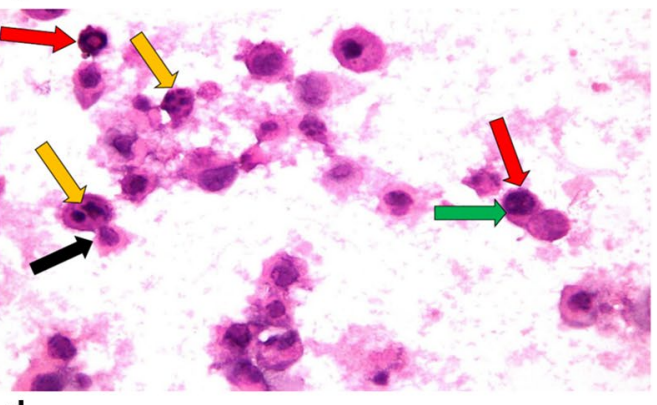

d

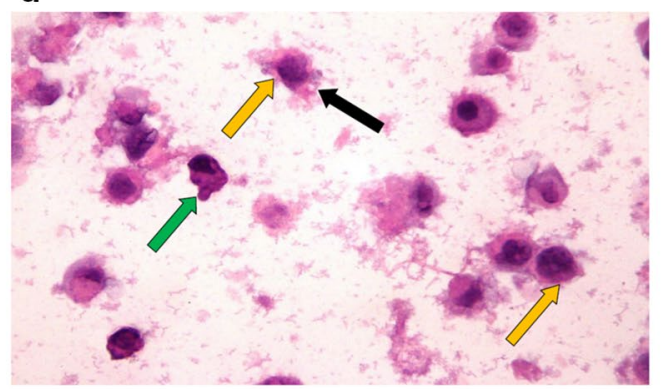

e

f
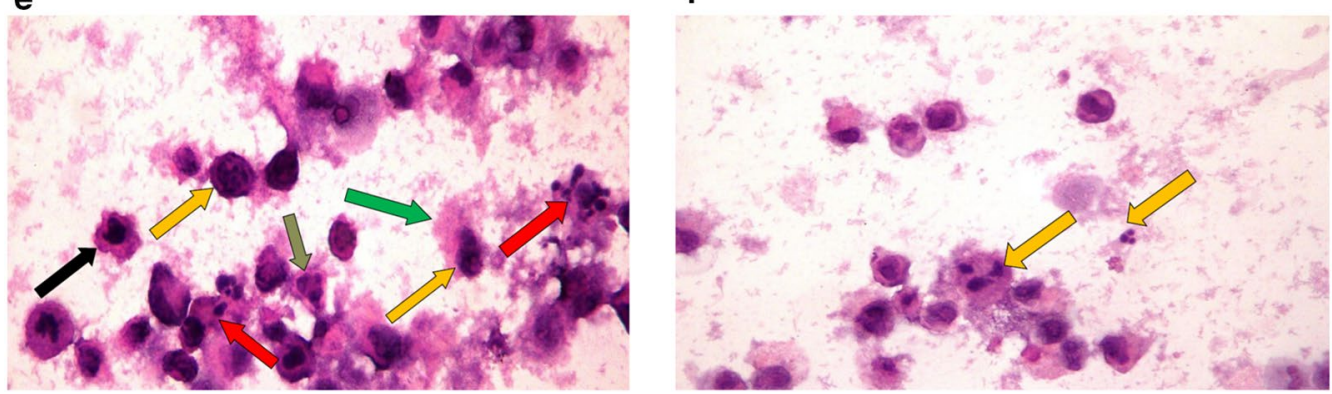

Fig. 9 Photomicrograph of the treated cells showing a peripheral chromatin condensation (yellow arrow); nuclear segregation (red arrow); irregular cell membrane (green arrow). b Nuclear fragmentation (yellow arrow); apoptotic body (black arrow) peripheral chromatin condensation (red arrow); nuclear segregation (green arrow). c Nuclear fragmentation (red Arrow), peripheral chromatin condensation (yellow arrow). d Necrotic swollen cells and clumping of the heterochromatin admixed with euchromatin (yellow arrow); membrane blabbing (green arrow) and ruptured cell membrane (black arrow). e Swollen necrotic cell with euchromatin admixed with heterochromatin (yellow arrow); ruptured cell membrane (green arrow); apoptotic cell with irregular cellular outline (back arrow); nuclear fragmentation (grey arrow); apoptotic bodies (red arrow). f Nuclear fragmentation (yellow arrow) 
carried out to test the anti-cancer and anti-inflammatory potential of SA, suggest that SA has a great potential as a cancer therapy/enhancer whether capsulated, free or accompanied with other anti-cancer drugs. However, its adverse effects on biological systems need further studies and experimentations in vivo, in order to decide whether it is better to use free or encapsulated SA and to know if they both would give the same effect in vivo as in vitro. Most of CaCo2, A549 and HFB4 cells cell control showed almost rounded, hyperchromatic nuclei and the cellular outline were almost regular without evidence of any folding. Only a few cells among control cells showed cellular and nuclear pleomorphism (Fig. 8). After $24 \mathrm{~h}$ post treatment with $\mathrm{IC}_{50}$ concentration of either free or nano capsulated SA showed the presence of apoptotic morphological changes was common including peripheral chromatin condensation, nucleolar segregation and irregular cell membrane (Fig. 9a-c). A number of apoptotic features such as nuclear fragmentation, apoptotic body that contains organelles were seen (Fig. 9b). Also some $\mathrm{CaCo} 2$ and A549 cells showed necrotic morphological changes such as cytoplasmic and nuclear swelling, clumping of the heterochromatin admixed with euchromatin, membrane blebbing that contain no organelles and ruptured cell membrane (Fig. 9d, e). In addition to the presence of cells indicating both necrotic and apoptotic features such as nuclear fragmentation and cytoplasmic swelling in the same cell (secondary necrosis) (Fig. 9f), some cells appear as apoptotic cell with irregular cellular outline and other showing apoptotic bodies that contains organelles (Fig. 9e).

\begin{abstract}
Abbreviations
A549: adenocarcinomic human alveolar basal epithelial cells; CaCo2: continuous line of heterogeneous human epithelial colorectal adenocarcinoma cells; HFB4: human normal fibroblast cells; MTT: 3-(4,5-dimethylthiazol-2-yl)-2,5-diphenyltetrazolium bromide Assay; $\mid \mathrm{C}_{50}$ : half maximal inhibitory concentration; NF-kB: nuclear factor kappa light chain enhancer of activated B cells; iNOS: inducible nitric oxide synthase gene; COX-2: cyclooxygenase-2; Blc-2: B-cell lymphoma 2; BAX: BCL2-associated X protein; P53: phospho tumor protein gene; DMSO: dimethyl sulfoxide; EDTA: ethylenediaminetetraacetic acid; PBS: phosphate-buffered saline; OD: optical density; RNA: ribonucleic acid; mRNA messenger RNA; cDNA: complementary deoxyribonucleic acid; RNase: ribonuclease; PCR: polymerase chain reaction; SD: standard deviation; SA: sinapic acid; FSA: free sinapic acid; NSA: nano-capsulated sinapic acid; DMEM: Dulbecco modified eagle's medium; RPMI 1640: Roswell park memorial institute 1640 medium; NT: non treated.
\end{abstract}

\section{Acknowledgements}

Authors extend their appreciation to the Research Center for Advanced Materials (RCAMS) at King Khalid University for supporting this work through research groups program under grant number RCAMS/KKU/006-19.

\section{Authors' contributions}

AFM, AEF, MAY, were a major contributor in writing the manuscript and processing analytical data, designed and led this research. DAB, MEA, WMAE, MSMN, TMMA, and HA designed and performed the experiments. NSA via Research Center for Advanced Materials (RCAMS) at King Khalid University supported this work. Professor YHJ made final editing and proofreading of the revised manuscript. All authors read and approved the final manuscript.

\section{Funding}

Research Center for Advanced Materials (RCAMS), King Khalid University, Grant No.: RCAMS/KKU/006-19.

\section{Availability of data and materials}

Not applicable.

\section{Competing interests}

The authors declare that they have no competing interests.

\section{Author details}

${ }^{1}$ Applied Research Department, Research and Development Sector, Egyptian Organization for Biological Products and Vaccines (VACSERA Holding Company), 51 Wezaret El-Zeraa St., Agouza, Giza, Egypt. ${ }^{2}$ Histology Department, Faculty of Medicine, Alazhar University, Damietta, Egypt. ${ }^{3}$ Histology Department, Faculty of Medicine, Alazhar University, Cairo, Egypt. ${ }^{4}$ The International Center for Advanced Researches (ICTAR- Egypt), Cairo, Egypt. ${ }^{5}$ Analytical Chemistry and Control Department, Hot Laboratories Center, Atomic Energy Authority of Egypt, P.O. 13759, Abu Zaabal, Cairo, Egypt. ${ }^{6}$ Research Centre for Advanced Materials Science (RCAMS), King Khalid University, P.O. Box 9004, Abha 61413, Saudi Arabia. ${ }^{7}$ Graduate Institute of Applied Science and Technology, National Taiwan University of Science and Technology, 43 Section 4 Keelung Road, Taipei 10607, Taiwan. ${ }^{8}$ Department of Chemical Engineering, National Taiwan University of Science and Technology, 43 Section 4 Keelung Road, Taipei 10607, Taiwan. ${ }^{9}$ Taiwan Building Technology Center, National Taiwan University of Science and Technology, 43 Section 4 Keelung Road, Taipei 10607, Taiwan.

Received: 3 May 2019 Accepted: 24 September 2019

Published online: 28 October 2019

\section{References}

1. Siegel L, Miller D, Jemal A (2016) Cancer statistics. CA Cancer J Clin 66(1):7-30

2. Ibrahim S, Khaled M, Mikhail N, Baraka H, Kamel H. Cancer incidence in Egypt: results of the national population-based cancer registry program. J Cancer Epidemiol; 2014. Article ID: 437971. http://dx.doi. org/10.1155/2014/437971

3. Siegel R, De Santis C, Virgo K, Stein K, Mariotto A, Smith T, Lin C (2012) Cancer treatment and survivorship statistics. CA Cancer J Clin 62(4):220-241

4. Yun J, Koh J, Kim H, Park J, Ryu H, Kim G, Lee T (2008) Anti-inflammatory effects of sinapic acid through the suppression of inducible nitric oxide synthase, cyclooxygase-2, and proinflammatory cytokines expressions via nuclear factor-kB inactivation. J Agric Food Chem 56(21):10265-10272

5. Nićiforović $\mathrm{N}$, Abramovič H (2014) Sinapic acid and its derivatives: natural sources and bioactivity. Compr Rev Food Sci Food Saf 13(1):34-51

6. Ayorinde F, Gelain V, Johnson J, Wan W (2000) Analysis of some commercial polysorbate formulations using matrix-assisted laser desorption/ionization time-of-flight mass spectrometry. Rapid Commun Mass Spectrom 14(22):2116-2124

7. Qian Z, Pollard W (2010) Macrophage diversity enhances tumor progression and metastasis. Cell 141(1):39-51

8. Shukla Y, Singh R (2011) Resveratrol and cellular mechanisms of cancer prevention. Ann NY Acad Sci 1215(1):1-8

9. Hudson A, Dinh A, Kokubun T, Simmonds S, Gescher A (2000) Characterization of potentially chemopreventive phenols in extracts of brown rice that inhibit the growth of human breast and colon cancer cells. Cancer Epidemiol Prev Biomarkers 9(11):1163-1170

10. Kampa M, Alexaki I, Notas G, Nifli P, Nistikaki A, Hatzoglou A, Gravanis A (2003) Antiproliferative and apoptotic effects of selective phenolic acids on T47D human breast cancer cells: potential mechanisms of action. Breast Cancer Res 6(2):R63 
11. Nagao T, Fumiko E, Okabe H (2001) Antiproliferative constituents in the plants 7. Leaves of Clerodendronbungei and leaves and bark of C. trichotomum. Biol Pharm Bull 24(11):1338-1341

12. Janakiraman K, Suresh S, Mariadoss V (2014) Influence of sinapic acid on induction of apoptosis in human laryngeal carcinoma cell line. Int J Modern Res Rev 2(5):165-170

13. Senawong T, Misuna S, Khaopha S, Nuchadomrong S, Sawatsitang P, Phaosiri C, Sripa B (2013) Histone deacetylase (HDAC) inhibitory and antiproliferative activities of phenolic-rich extracts derived from the rhizome of Hydnophytum formicarum Jack: sinapinic acid acts as HDAC inhibitor. BMC Complement Altern Med 13(1):232

\section{Publisher's Note}

Springer Nature remains neutral with regard to jurisdictional claims in published maps and institutional affiliations.

\section{Submit your manuscript to a SpringerOpen ${ }^{\circ}$ journal and benefit from:}

- Convenient online submission

- Rigorous peer review

- Open access: articles freely available online

- High visibility within the field

- Retaining the copyright to your article

Submit your next manuscript at $\boldsymbol{\sim}$ springeropen.com 